\title{
Prevalence and factors associated with depressive and anxiety symptoms among Palestinian medical students
}

\author{
Ramzi Shawahna ${ }^{1,2}$, Suhaib Hattab ${ }^{1 *}$, Rami Al-Shafei ${ }^{3}$ and Mahmoud Tab'ouni ${ }^{3}$
}

\begin{abstract}
Background: Co-existence of depression and anxiety can be associated with severe detrimental consequences to the physical, mental and social wellbeing of the affected populations. This study was conducted to determine prevalence of depressive and anxiety symptoms among Palestinian medical students and to investigate associations between sociodemographic factors of the students with depressive and anxiety symptoms.

Methods: This study was conducted in a cross-sectional observational design using a questionnaire in the period between September 2018 and April 2019 in a major university in the West Bank of Palestine. Depressive symptoms were assessed using the Beck Depression Inventory-II (BDI-II) and anxiety symptoms were assessed using the Beck Anxiety Inventory (BAI). The questionnaire also collected the sociodemographic characteristics of the students. Reliability of the questionnaire was tested using the test re-test method. A total of 425 medical students were invited to participate in the study.

Results: Of those invited, 286 students completed the questionnaire, giving a response rate of $67.3 \%$. More than half (56.6\%) of the students had minimal depression, 20.3\% had mild depression, 14.0\% had moderate depression, 9.1\% had severe depression, $23.4 \%$ had no anxiety, 29.7\% had mild to moderate anxiety, $25.5 \%$ had moderate to severe anxiety, and $21.3 \%$ had severe anxiety. Multiple linear regression analysis showed that academic stage ( $p$ value $<0.01$ ), Grade Point Average ( $p$-value $<0.01$ ), mental health status ( $p$-value $<0.001$ ), ever attempted suicide $(p$-value $<0.05)$, and religious commitment $(p$-value $<0.01)$ were predictors of BDI-II scores. Multiple linear regression analysis showed that academic stage $(p$-value $<0.05)$ and mental health status $(p$-value $<0.001)$ were predictors of BAl scores.

Conclusions: Depressive and anxiety symptoms were prevalent among Palestinian medical students in a major university in the West Bank of Palestine. Interventions might be designed to improve self-rated mental health of medical students in their academic years, ameliorate study conditions, and provision of counseling services to improve spirituality might be effective in reducing symptoms of depression and anxiety among medical students in Palestine. Future studies are still needed to investigate if these interventions could be useful in reducing depressive and anxiety symptoms among Palestinian medical students.
\end{abstract}

Keywords: Anxiety, Depression, Medical students, Palestine, Middle East

\footnotetext{
* Correspondence: suhaib.hattab@najah.edu

'Department of Physiology, Pharmacology and Toxicology, Faculty of

Medicine and Health Sciences, An-Najah National University, New Campus,

Building 19, P.O. Box 7, Nablus, Palestine

Full list of author information is available at the end of the article
}

\section{$\triangle B M C$}

(c) The Author(s). 2020 Open Access This article is licensed under a Creative Commons Attribution 4.0 International License, which permits use, sharing, adaptation, distribution and reproduction in any medium or format, as long as you give appropriate credit to the original author(s) and the source, provide a link to the Creative Commons licence, and indicate if changes were made. The images or other third party material in this article are included in the article's Creative Commons licence, unless indicated otherwise in a credit line to the material. If material is not included in the article's Creative Commons licence and your intended use is not permitted by statutory regulation or exceeds the permitted use, you will need to obtain permission directly from the copyright holder. To view a copy of this licence, visit http://creativecommons.org/licenses/by/4.0/ The Creative Commons Public Domain Dedication waiver (http://creativecommons.org/publicdomain/zero/1.0/) applies to the data made available in this article, unless otherwise stated in a credit line to the data. 


\section{Background}

Psychological distress among university students has been a concern for public health authorities around the globe [1]. Among university students, medical students are particularly more vulnerable to psychological distress and morbidity [1-7]. Previous studies have shown that depression and anxiety are highly prevalent among medical students in different countries around the world [2$25]$ including countries in the Middle East [2, 3, 16, 2125].

A recent meta-analysis of 77 different studies reported a global depression prevalence rate of $28.0 \%$ among medical students [18]. Some studies have reported alarming rates of depression and anxiety among medical students. A study conducted at the Royal College of Surgeons in Bahrain showed that $40 \%$ of participants had depressive symptoms and $51 \%$ had anxiety symptoms [2]. Similarly, a study conducted at the Foundation University Medical College in Pakistan reported that $51 \%$ of students had depression and anxiety [4]. Other studies have reported prevalence rates of depression and anxiety above 35\% among medical students [1, 6, 15].

Prevalence rates of depression and anxiety were shown to be higher among medical students compared to their age-matched peers in both general population and those studying non-medical subjects [6, 7, 26-28]. Such high prevalence rates of depression and anxiety among medical students were attributed to personal and/or institutional factors [29]. Depression is characterized by many symptoms like sadness, excessive loss of interests and/or pleasure, feeling guilty or low self-esteem, disturbances in sleep and/or appetite, feeling tired, and decreased ability to concentrate [30, 31]. Anxiety is characterized by an inappropriately excessive and/or persistent worry that is often accompanied by symptoms like tachycardia, tremors, restlessness, fatigue, poor concentration, irritability, and disturbances in sleep pattern [32]. Coexistence of depression and anxiety can be highly disabling and might result in severe detrimental consequences to the physical, mental and social wellbeing of the affected populations [33, 34]. Depression and anxiety might have severe adverse consequences on the academic performance of medical students, their reported quality of life, contribute to substance abuse, decrease empathy, and academic dishonesty $[1,35,36]$. Previous studies have also shown that poor mental health was a predictor of later psychological distress among practicing physicians [37, 38]. Considering the severity of these detrimental consequences, understanding the prevalence of depression and anxiety among medical students in Palestine becomes imperative before designing and implementing interventions to improve mental health, create supportive environments, and reduce psychological distress among medical students.
While there were many studies investigating the prevalence of depressive and anxiety symptoms among medical students and the potential sociodemographic characteristics associated with high prevalence rates in different countries including some Middle Eastern countries, little is known on the prevalence of depression and anxiety among Palestinian medical students. Moreover, little is known on the sociodemographic factors that could be associated with depressive and anxiety symptoms among Palestinian medical students. Therefore, this study was conducted to determine the prevalence of depressive and anxiety symptoms among Palestinian medical students and to investigate associations between sociodemographic factors and depressive and anxiety symptoms.

\section{Methods}

\section{Study context}

The study was conducted in one of the major universities in the West Bank of Palestine. The Doctor of Medicine (MD) program at the university where the study was conducted is a 165 -credit hour program that students often complete in 6 academic years. Students complete 135 credit hours of basic courses and 130 credit hours of clinical courses and training. Graduates of the MD program are licensed to assume practitioner roles in all healthcare establishments providing primary, secondary, and tertiary healthcare services after completing a compulsory hospital-based training program. The present study was conducted in the period between September 2018 and April 2019 to assess prevalence of depressive and anxiety symptoms among the medical students. The study period covered both 1 st and 2nd semesters of the academic year 2018/2019. All students enrolled in the MD program at the time of the study were either Palestinians who were born and raised in the West Bank of Palestine or had Palestinian heritage. Students identified themselves as Muslims or Christians.

\section{Study settings}

Students in the basic stage (academic year 1 to academic year 3) of medical school were recruited on campus. Students in the clinical stage (academic year 4 to academic year 6) were recruited in their training sites in different hospitals in the West Bank of Palestine.

\section{Study design}

This study was conducted in a cross-sectional observational design using a questionnaire. The questionnaire collected sociodemographic characteristics of the students and incorporated two inventories to measure depressive and anxiety symptoms. The Beck Depression Inventory-II (BDI-II) was used to assess the presence of depressive symptoms [39]. The Beck Anxiety Inventory 
(BAI) was used to assess the presence of anxiety symptoms [40].

\section{Study population and sample size calculation}

The sample size needed for this study was calculated using an online sample size calculator (http://www.raosoft.com/samplesize.html). The sample size was calculated based on a population of 2500 medical students using a $95 \%$ confidence interval (CI) and a $5 \%$ margin of error. The sample size was estimated based on arbitrary prevalence rate of depression and anxiety of $35 \%$ based on previous studies in the region $[1-7,16]$. The sample size needed for this study was 307 medical students.

To achieve the sample size needed for this study, we decided to invite 425 medical students assuming a response rate of approximately $72 \%$ that was informed by our previous studies using a questionnaire as the study tool $[41-50]$. The target sample was stratified by academic year. Considering the number of students in each academic year, the target sample was stratified by academic year as $24 \%$ from the 1st year students, $20.9 \%$ from the 2nd year students, $16.2 \%$ from the 3rd year students, $16.9 \%$ from the 4 th year students, $10.1 \%$ from the 5th year students, and $11.8 \%$ from the 6 th year students.

Email was the main channel of communication between the medical students and the academic staff at the university where the study was conducted. A list of emails of all medical students enrolled in the MD program was obtained from the registrar office after permission was granted by the administration of the university. Contacts of strata were selected randomly and invitations were sent to potential participants via email. Those who did not respond receive 3 reminders, each was 1 week apart.

\section{The study tool}

The study tool was a questionnaire that contained three sections. The first section collected sociodemographic characteristics of the students like age, gender, place where the student was born and raised before they were enrolled in the MD program, place of current residence while studying medicine, motives for studying medicine, if given a chance, would they study medicine again, academic stage (year of study), their Grade Point Average (GPA) out of 4, if they had ever failed a subject during their study of medicine, self-assessment of their mental health status (on a Likert-scale of 1-5, 1= not at all mentally disturbed, $5=$ having serious mental health problems), if they had ever attempted suicide, monthly household income, self-assessment of their financial status (on a Likert-scale of $1-5,1=$ completely dissatisfied with my financial status, $5=$ completely satisfied with my financial status), marital status, self-assessment of their social life (on a Likert-scale of 1-5, 1= completely dissatisfied with my social life, $5=$ completely satisfied with my social life), and self-assessment of their religious commitment (on a Likert-scale of $1-5,1=$ completely dissatisfied with my religious commitment, $5=$ completely satisfied with my religious commitment).

The second section contained the 21-item BDI-II. The 21 items of the BDI-II are shown in Additional file 1. The tool purported to screen for the presence of depressive symptoms. Participants could obtain a cumulative score of minimum of 0 to a maximum 63 . Scores $0-13$ indicated minimal depression, scores 14-19 indicated mild depression, scores 20-28 indicated moderate depression, and scores 29-63 indicated severe depression $[39,51]$. The BDI-II was shown to have a sensitivity of $87 \%$ and a specificity of $79 \%$ [52].

The third section contained the 21-item BAI. The 21 items of the BAI are shown in Additional file 2. The tool purported to screen for the presence of anxiety symptoms. Again, the participant had to rate each item on a scale of $0-3$. Scores $0-9$ indicated normal or no anxiety, scores 10-18 indicated mild to moderate anxiety, scores 19-29 indicated moderate to severe anxiety, and scores $30-63$ indicated severe anxiety $[40,53]$.

\section{Reliability}

The questionnaire was in Arabic language. Validation of the Arabic versions of the BDI-II and BAI was reported previously [54-56]. The Arabic version of BDI-II and BAI were found to be internally consistent with a Cronbach's alpha of 0.90 [54-56]. Prior to this study, a pilot was conducted with 29 medical students to assess the questionnaire for readability and comprehension $[45,46$, 49]. The test re-rest reliability was excellent for both BDI-II and BAI as shown by Pearson's r of 0.97 (95\% CI 0.94 to 0.99 ) with a $p$-value $<0.001$ for BDI-II and Pearson's $\mathrm{r}$ of 0.96 (95\% CI 0.91 to 0.98$)$ with a $p$-value < 0.001 for BAI.

\section{Ethical approval}

The study was conducted in accordance with the regulations and ethics followed at An-Najah National University and in compliance with the Declaration of Helsinki. The study received ethical approval from the Institutional Review Board (IRB) of An-Najah National University (Protocol \# April-04-2018). Each participant provided written informed consent before taking part in the study.

\section{Statistical analysis}

The data collected in this study were entered into IBM SPSS for Windows V.21.0 (IBM). The KolmogorovSmirnov test was used to assess if the data were normally distributed or not. As the data were not normally distributed, median, lower quartile (Q1) and upper 
quartile (Q3) with interquartile range (IQR) were used. Differences between scores were compared for statistical significance using Mann-Whitney $U$ test or Kruskal Wallis tests. Correlation was investigated using Spearman's correlation coefficients. We conducted a multiple linear regression analyses to identify the independent characteristics that were predictors of higher depression and anxiety scores. To control for confounders, characteristics that had a $p$-value $<0.05$ in the Mann-Whitney $U$ test, Kruskall-Wallis tests, and/or correlations were retained in the multiple linear regression. The goodness of fit of the regression was assessed using the adjusted $\mathrm{R}$-squared with a $p$-value $\leq 0.05$. Collinearity statistics were used to evaluate the variance inflation factor (VIF) and tolerance in the linear regression analyses. The VIF values were less than 1.87 and the tolerance values were greater than 1.04 indicated no multicollinearity problems with the independent variables $[41,45,57,58]$. Statistical significance was considered when the $p$-value was $\leq 0.05$.

\section{Results}

Response rate and characteristics of the participants

The questionnaire was distributed to 425 medical students. Valid and complete questionnaire were received from 286 participants giving a response rate of $67.3 \%$.

The median age of the students who participated in the study was 20 with an IQR of 3 years and the median GPA was 3.2 with an IQR of 0.69 . Of all students, $60.8 \%$ were female in gender, and $69.2 \%$ were born and raised in cities. However, $47.6 \%$ of the students were living in dormitories during their medical studies. When asked about their motives to study medicine, $81.8 \%$ of the students cited personal motives and $73.4 \%$ stated that they would study medicine if they were given a second chance. Of all students, $43.4 \%$ were in their clinical stage of medical studies (year 4 to year 6 ) and $74.5 \%$ of them stated that they had never failed a subject during their medical studies. In this study, $63.3 \%$ of the students had high monthly income, $3.1 \%$ were either married or engaged, and $4.5 \%$ stated that they had attempted suicide. When asked to self-rate their mental health status, financial status, social life, and religious commitment, 41.6, 56.6, 59.5, and $36.7 \%$ of the students rated these items 4 or 5 on the 5 -point Likert-scale. The sociodemographic characteristics of the study participants are shown in Table 1.

\section{Prevalence of depressive and anxiety symptoms among medical students}

When the BDI-II was self-administered, moderate depressive symptoms were prevalent in $14.0 \%$ of the students and $25.5 \%$ of the students had moderate to severe anxiety. Severe depressive symptoms were prevalent in $9.1 \%$ of the students and severe anxiety was prevalent in
Table 1 Characteristics of the study participants $(n=286)$

Characteristic n $\%$

Age (years)

$\begin{array}{lll}<20 & 103 & 36.0\end{array}$

$\geq 20$

183

64.0

Gender

$\begin{array}{lll}\text { Male } & 112 & 39.2\end{array}$

Female

174

Place of residence (born and raised)

$\begin{array}{lll}\text { City } & 198 & 69.2 \\ \text { Village } & 82 & 28.7 \\ \text { Refugee camp } & 6 & 2.1\end{array}$

Place of current residence during study of medicine

Family home $\quad 150 \quad 52.4$

$\begin{array}{lll}\text { Dormitory } & 136 & 47.6\end{array}$

Motives for studying medicine

$\begin{array}{lll}\text { Personal motives } & 234 & 81.8\end{array}$

$\begin{array}{lll}\text { Family motives } & 44 & 15.4\end{array}$

$\begin{array}{lll}\text { Undeclared } & 8 & 2.8\end{array}$

If given a chance, would study medicine again?

$\begin{array}{lll}\text { No } & 76 & 26.6\end{array}$

$\begin{array}{lll}\text { Yes } & 210 & 73.4\end{array}$

Academic stage

Basic (academic years 1-3) $\quad 162 \quad 56.6$

Clinical (academic years 4-6) $\quad 124 \quad 43.4$

Grade Point Average (GPA) out of 4

$\begin{array}{lll}<3 & 89 & 31.1\end{array}$

$\begin{array}{lll}>3 & 197 & 68.9\end{array}$

Ever failed a subject during your study of medicine

$\begin{array}{lll}\text { No } & 213 & 74.5\end{array}$

$\begin{array}{lll}\text { Yes } & 73 & 25.5\end{array}$

Mental health status (self-assessed on a Likert-scale of 1-5)

1196.6

$\begin{array}{lll}2 & 59 & 20.6\end{array}$

$\begin{array}{lll}3 & 89 & 31.1\end{array}$

$\begin{array}{lll}4 & 94 & 32.9\end{array}$

$\begin{array}{lll}5 & 25 & 8.7\end{array}$

Ever attempted suicide

$\begin{array}{lll}\text { No } & 273 & 95.5\end{array}$

$\begin{array}{lll}\text { Yes } & 13 & 4.5\end{array}$

Monthly household income (in US dollars)

Low $(<850) \quad 15 \quad 5.2$

Medium (850-1400) $\quad 90 \quad 31.5$

High (> 1400) $181 \quad 63.3$

Financial status (self-assessed on a Likert-scale of 1-5)

1

4

1.4 
Table 1 Characteristics of the study participants $(n=286)$ (Continued)

\begin{tabular}{lcc}
\hline Characteristic & $\mathrm{n}$ & $\%$ \\
\hline 2 & 24 & 8.4 \\
3 & 96 & 33.6 \\
4 & 105 & 36.7 \\
5 & 57 & 19.9 \\
Marital status & & \\
Single & 277 & 96.9 \\
Engaged/Married & 9 & 3.1 \\
Social life (self-assessed on a Likert-scale of $\mathbf{1 - 5}$ & \\
1 & 9 & 3.1 \\
2 & 33 & 11.5 \\
3 & 74 & 25.9 \\
4 & 96 & 33.6 \\
5 & 74 & 25.9 \\
Religious commitment (self-assessed on a Likert-scale of $\mathbf{1 - 5}$ \\
1 & 26 & 9.1 \\
2 & 41 & 14.3 \\
3 & 114 & 39.9 \\
4 & 96 & 33.6 \\
5 & 9 & 3.1 \\
\hline
\end{tabular}

$21.3 \%$ of the students. Table 2 shows depressive and anxiety symptoms as indicated by BDI-II and BAI scores.

In this study, moderate correlation was shown between scores of BDI-II and BAI (Spearman's rho $=0.60, p$-value $<0.001)$.

\section{Association between characteristics of the students with depressive symptoms}

In this study, the median BDI-II score was significantly ( $p$-value $<0.05)$ higher for students who cited family motives behind their choice to study medicine compared to those who cited personal motives or those who did not declare their motives. Similarly, the median BDI-II score was significantly $(p$-value $<0.05)$ higher for students who stated that they would not study medicine again if they were given a second chance compared to those who stated that they would. Students who were in the clinical stage (academic year 4 to academic year 6) had significantly ( $p$-value $<0.01$ ) lower BDI-II scores compared to students in the basic stage (academic year 1 to academic year 3). Students who had higher GPA and those who did not fail any subject during their medical studies had significantly ( $p$-value <0.05) lower BDI-II scores. Students who stated that they attempted suicide had significantly $(p$-value $<0.01)$ higher BDI-II scores than those who did not attempt suicide. Students who self-rated their mental health status, financial status, social life, and religious commitment as low had significantly ( $p$-value $<0.001$ ) higher BDI-II scores than those who self-rated these items higher.

Characteristics like age, gender, place where the student was born and raised, household income, and marital status were not significantly associated with the BDIII scores ( $p$-value $>0.05)$. Details of the associations between characteristics of the participants and symptoms of depression are shown in Table 3.

We conducted a multiple linear regression analysis to control for confounding effects in a trial to explain the variance in BDI-II scores that were associated with some characteristics of the students who participated in this study. When characteristics that were shown to be significantly associated with BDI-II scores in the MannWhitney U, Kruskal-Wallis, and correlation tests were retained in the multiple linear regression analysis, characteristics like academic stage $(p$-value $<0.01)$, GPA $(p$ value $<0.01)$, mental health status $(p$-value $<0.001)$, ever attempted suicide $(p$-value $<0.05)$, and religious commitment $(p$-value $<0.01)$ remained significantly associated.

Other variables like motives for studying medicine, would study medicine again if given a second chance, self-rated financial status and social life were no longer significantly associated ( $p$-value $>0.05$ ). Details of the multiple linear analysis are shown in Table 4.

\section{Association between characteristics of the students with anxiety symptoms}

Anxiety symptoms as indicated by BAI scores were significantly higher $(p$-value $<0.05)$ in students who were less than 20 years old. Similar to BDI-II scores, BAI scores were significantly higher $(p$-value $<0.05)$ for students who cited family motives behind their choice to study medicine compared to those who cited personal motives or those who did not declare their motives.

Table 2 Prevalence of depressive and anxiety symptoms among the study participants $(n=286)$

\begin{tabular}{llllll}
\hline Depression symptoms & $\mathrm{n}$ & $\%$ & Anxiety symptoms & $\mathrm{n}$ & $\%$ \\
\hline Minimal depression (BDI-II scores 0-13) & 162 & 56.6 & Normal or no anxiety (BAI scores 0-9) & 67 & 23.4 \\
Mild depression (BDI-II scores 14-19) & 58 & 20.3 & Mild to moderate anxiety (BAI scores 10-18) & 85 & 29.7 \\
Moderate depression (BDI-II scores 20-28) & 40 & 14.0 & Moderate to severe anxiety (BAl scores 19-29) & 73 & 25.5 \\
Severe depression (BDI-II scores 29-63) & 26 & 9.1 & Severe anxiety (BAl scores 30-63) & 61 & 21.3 \\
\hline
\end{tabular}


Table 3 Association between characteristics of the participants and symptoms of depression

\begin{tabular}{|c|c|c|c|c|c|c|c|c|c|c|}
\hline Characteristic & $n$ & $\%$ & Median & Q3 & Q1 & IQR & Mean rank & $\boldsymbol{p}$-value & Correlation coefficient & $p$-value \\
\hline \multicolumn{11}{|l|}{ Age (years) } \\
\hline$<20$ & 103 & 36.0 & 13.0 & 20.0 & 8.0 & 12.0 & 152.3 & 0.177 & -0.02 & 0.699 \\
\hline$\geq 20$ & 183 & 64.0 & 11.0 & 19.0 & 6.0 & 13.0 & 138.6 & & & \\
\hline \multicolumn{11}{|l|}{ Gender } \\
\hline Male & 112 & 39.2 & 12.0 & 19.0 & 7.0 & 12.0 & 144.0 & 0.941 & 0.01 & 0.895 \\
\hline Female & 174 & 60.8 & 12.0 & 19.0 & 6.0 & 13.0 & 143.2 & & & \\
\hline
\end{tabular}

Place of residence (born and raised)

$\begin{array}{llllllll}\text { City } & 198 & 69.2 & 12.0 & 19.0 & 7.0 & 12.0 & 145.4 \\ \text { Village } & 82 & 28.7 & 11.0 & 20.5 & 6.0 & 14.5 & 141.0 \\ \text { Refugee camp } & 6 & 2.1 & 7.5 & 15.0 & 2.3 & 12.8 & 113.4\end{array}$

Place of current residence during study of medicine

$\begin{array}{llllllll}\text { Family home } & 150 & 52.4 & 11.0 & 18.0 & 6.0 & 12.0 & 134.7 \\ \text { Dormitory } & 136 & 47.6 & 13.5 & 20.0 & 8.0 & 12.0 & 153.2\end{array}$

\section{Motives for studying medicine}

$\begin{array}{llllllll}\text { Personal motives } & 234 & 81.8 & 11.0 & 18.0 & 6.0 & 12.0 & 137.9 \\ \text { Family motives } & 44 & 15.4 & 15.0 & 21.3 & 10.0 & 11.3 & 170.1 \\ \text { Undeclared } & 8 & 2.8 & 12.5 & 19.5 & 11.8 & 7.8 & 162.1\end{array}$

If given a chance, would study medicine again?

$\begin{array}{llllllll}\text { No } & 76 & 26.6 & 13.5 & 21.0 & 8.0 & 13.0 & 160.4 \\ \text { Yes } & 210 & 73.4 & 11.0 & 18.0 & 6.0 & 12.0 & 137.4\end{array}$

Academic stage

Basic (academic years 1-3) $\quad 162 \quad 56.6 \quad 13.0$

Clinical (academic years 4-6) 124

$\begin{array}{llllllll}<3 & 89 & 31.1 & 15.0 & 25.0 & 8.0 & 17.0 & 160.4 \\ >3 & 197 & 68.9 & 11.0 & 18.0 & 6.0 & 12.0 & 135.9\end{array}$

Ever failed a subject during your study of medicine

$\begin{array}{llllllll}\text { No } & 213 & 74.5 & 11.0 & 18.0 & 6.0 & 12.0 & 138.2 \\ \text { Yes } & 73 & 25.5 & 15.0 & 22.0 & 7.0 & 15.0 & 159.1\end{array}$

Mental health status (self-assessed on a Likert-scale of 1-5)

$\begin{array}{llllllll}1 \text { (least) } & 19 & 6.6 & 30.0 & 34.5 & 19.0 & 15.5 & 240.9 \\ 2 & 59 & 20.6 & 19.0 & 26.0 & 15.0 & 11.0 & 206.2 \\ 3 & 89 & 31.1 & 13.0 & 19.0 & 9.0 & 10.0 & 155.4 \\ 4 & 94 & 32.9 & 7.0 & 11.8 & 4.0 & 7.8 & 93.4 \\ 5 \text { (most) } & 25 & 8.7 & 4.0 & 8.0 & 2.0 & 6.0 & 67.6\end{array}$

Ever attempted suicide

\begin{tabular}{|c|c|c|c|c|c|c|c|c|c|c|}
\hline No & 273 & 95.5 & 11.0 & 19.0 & 6.0 & 13.0 & 140.3 & 0.003 & 0.16 & 0.007 \\
\hline Yes & 13 & 4.5 & 21.0 & 35.0 & 13.0 & 22.0 & 210.1 & & & \\
\hline \multicolumn{11}{|c|}{ Monthly household income in US dollars } \\
\hline Low $(<850)$ & 15 & 5.2 & 14.0 & 21.0 & 8.0 & 13.0 & 161.8 & \multirow[t]{3}{*}{0.194} & \multirow[t]{3}{*}{-0.1} & \multirow[t]{3}{*}{0.091} \\
\hline Medium (850-1400) & 90 & 31.5 & 13.0 & 20.8 & 7.3 & 13.5 & 153.8 & & & \\
\hline High (> 1400) & 181 & 63.3 & 11.0 & 18.0 & 6.0 & 12.0 & 136.9 & & & \\
\hline nclal & a L & , & $1-$ & & & & & & & \\
\hline 1 & 4 & 1.4 & 9.5 & 20.3 & 8.0 & 12.3 & 151.5 & 0.003 & 18 & 0.003 \\
\hline
\end{tabular}


Table 3 Association between characteristics of the participants and symptoms of depression (Continued)

\begin{tabular}{|c|c|c|c|c|c|c|c|c|c|c|}
\hline Characteristic & $n$ & $\%$ & Median & Q3 & Q1 & IQR & Mean rank & $p$-value & Correlation coefficient & $p$-value \\
\hline 2 & 24 & 8.4 & 17.5 & 24.5 & 14.8 & 9.8 & 200.0 & & & \\
\hline 3 & 96 & 33.6 & 13.0 & 21.0 & 7.0 & 14.0 & 149.6 & & & \\
\hline 4 & 105 & 36.7 & 12.0 & 18.0 & 6.0 & 12.0 & 136.5 & & & \\
\hline 5 & 57 & 19.9 & 9.0 & 16.0 & 4.0 & 12.0 & 121.9 & & & \\
\hline \multicolumn{11}{|l|}{ Marital status } \\
\hline Single & 277 & 96.9 & 12.0 & 19.0 & 7.0 & 12.0 & 143.2 & 0.762 & 0.02 & 0.762 \\
\hline Engaged/Married & 9 & 3.1 & 15.0 & 21.0 & 6.0 & 15.0 & 151.7 & & & \\
\hline \multicolumn{11}{|c|}{ Social life (self-assessed on a Likert-scale of 1-5) } \\
\hline 1 & 9 & 3.1 & 20.0 & 24.0 & 18.0 & 6.0 & 214.1 & 0.000 & -0.34 & 0.000 \\
\hline 2 & 33 & 11.5 & 21.0 & 27.0 & 15.0 & 12.0 & 215.5 & & & \\
\hline 3 & 74 & 25.9 & 13.0 & 20.8 & 6.0 & 14.8 & 149.6 & & & \\
\hline 4 & 96 & 33.6 & 10.0 & 15.0 & 6.0 & 9.0 & 126.6 & & & \\
\hline 5 & 74 & 25.9 & 9.0 & 16.0 & 4.0 & 12.0 & 118.6 & & & \\
\hline \multicolumn{11}{|c|}{ Religious commitment (self-assessed on a Likert-scale of 1-5) } \\
\hline 1 & 26 & 9.1 & 20.0 & 25.8 & 10.3 & 15.5 & 192.9 & 0.000 & -0.29 & 0.000 \\
\hline 2 & 41 & 14.3 & 17.0 & 24.0 & 11.0 & 13.0 & 181.5 & & & \\
\hline 3 & 114 & 39.9 & 12.0 & 18.0 & 6.0 & 12.0 & 141.7 & & & \\
\hline 4 & 96 & 33.6 & 10.0 & 15.0 & 4.0 & 11.0 & 120.1 & & & \\
\hline 5 & 9 & 3.1 & 8.0 & 13.0 & 1.0 & 12.0 & 100.4 & & & \\
\hline
\end{tabular}

Q1 1st quartile, Q3 3rd quartile, IQR interquartile range

Again, BAI scores were significantly higher $(p$-value < 0.001 ) for students who were in their basic stage (academic year 1 to academic year 3) of medical studies compared to those in the clinical stage (academic year 4 to academic year 6). Students who stated that they had attempted suicide had significantly ( $p$-value $<0.01$ ) higher BAI scores than those who did not attempt suicide. Students with low income had significantly higher ( $p$-value <0.05) BAI scores compared to those with higher income. Students who self-rated their mental health status, financial status, social life, and religious commitment as low had significantly ( $p$-value $<0.01$ ) higher BAI scores than those who self-rated them higher.
Characteristics like gender, place where the student was born and raised, place of residence during medical studies, would study medicine again if given a second chance, GPA, ever failed a subject, and marital status were not significantly associated with the BAI scores $(p$ value $>0.05$ ). Details of the associations between characteristics of the participants and symptoms of anxiety are shown in Table 5.

Again, we conducted a multiple linear regression analysis to control for confounding effects in a trial to explain the variance in BAI scores that were associated with some characteristics of the students who participated in this study. When characteristics that were shown to be significantly associated with BAI scores in

Table 4 Multiple linear regression analysis of association between characteristics of the participants and depression symptoms

\begin{tabular}{|c|c|c|c|c|c|}
\hline Variable & Unstandardized Coefficients & S.E. & Standardized Coefficients & t & $\boldsymbol{p}$-value \\
\hline Motives for studying medicine & -0.12 & 0.82 & -0.01 & -0.14 & 0.888 \\
\hline If given a chance, would study medicine again & 0.20 & 1.13 & 0.01 & 0.18 & 0.856 \\
\hline Academic stage & -2.86 & 0.96 & -0.14 & -2.96 & 0.003 \\
\hline Grade Point Average (GPA) & -2.84 & 0.99 & -0.13 & -2.87 & 0.004 \\
\hline Mental health status & -4.54 & 0.47 & -0.49 & -9.58 & 0.000 \\
\hline Ever attempted suicide & 5.12 & 2.16 & 0.11 & 2.37 & 0.019 \\
\hline Financial status & -0.42 & 0.51 & -0.04 & -0.83 & 0.407 \\
\hline Social life & -0.73 & 0.49 & -0.08 & -1.50 & 0.135 \\
\hline Religious commitment & -1.46 & 0.49 & -0.15 & -2.99 & 0.003 \\
\hline
\end{tabular}


Table 5 Association between characteristics of the participants and symptoms of anxiety

\begin{tabular}{lllllllllrr}
\hline Characteristic & $\mathrm{n}$ & $\%$ & Median & $\mathrm{Q} 3$ & $\mathrm{Q} 1$ & IQR & Mean rank & $\boldsymbol{p}$-value & Correlation coefficient & $\boldsymbol{p}$-value \\
\hline $\begin{array}{l}\text { Age (years) } \\
\quad 20\end{array}$ & 103 & 36.0 & 20.0 & 29.5 & 11.5 & 18.0 & 156.3 & 0.050 & -0.11 \\
$\quad \begin{array}{l}20 \\
\text { Gender }\end{array}$ & 183 & 64.0 & 16.0 & 26.0 & 9.0 & 17.0 & 136.3 & & \\
$\quad \begin{array}{l}\text { Male } \\
\text { Female }\end{array}$ & 112 & 39.2 & 15.5 & 24.0 & 9.8 & 14.3 & 135.0 & 0.163 & 0.08 \\
\end{tabular}

Place of residence (born and raised)

$\begin{array}{llllllll}\text { City } & 198 & 69.2 & 18.0 & 27.0 & 12.0 & 15.0 & 145.6 \\ \text { Village } & 82 & 28.7 & 18.0 & 27.0 & 8.0 & 19.0 & 136.0 \\ \text { Refugee camp } & 6 & 2.1 & 26.0 & 34.8 & 13.5 & 21.3 & 175.0\end{array}$

Place of current residence during study of medicine

$\begin{array}{llllllll}\text { Family home } & 150 & 52.4 & 17.5 & 26.5 & 9.0 & 17.5 & 136.3 \\ \text { Dormitory } & 136 & 47.6 & 18.0 & 28.3 & 12.0 & 16.3 & 151.5 \\ \text { Motives for studying medicine } & & & & & & & \\ \text { Personal motives } & 234 & 81.8 & 18.0 & 26.8 & 10.0 & 16.8 & 138.6 \\ \text { Family motives } & 44 & 15.4 & 22.0 & 29.3 & 11.8 & 17.5 & 166.3 \\ \text { Undeclared } & 8 & 2.8 & 16.5 & 28.8 & 15.0 & 13.8 & 160.8\end{array}$

If given a chance, would study medicine again?

$\begin{array}{llllllll}\text { No } & 76 & 26.6 & 17.5 & 27.3 & 12.0 & 15.3 & 146.2 \\ \text { Yes } & 210 & 73.4 & 18.0 & 27.0 & 10.0 & 17.0 & 142.5\end{array}$

\section{Academic stage}

$\begin{array}{llllllll}\text { Basic (academic years 1-3) } & 162 & 56.6 & 21.0 & 30.0 & 12.0 & 18.0 & 158.6\end{array}$

$\begin{array}{llllllll}\text { Clinical (academic years 4-6) } & 124 & 43.4 & 15.0 & 22.0 & 8.8 & 13.3 & 123.8\end{array}$

Grade Point Average (GPA) out of 4

$\begin{array}{llllllll}<3 & 89 & 31.1 & 20.0 & 28.0 & 10.0 & 18.0 & 150.5 \\ >3 & 197 & 68.9 & 18.0 & 27.0 & 10.0 & 17.0 & 140.3\end{array}$

Ever failed a subject during study of medicine

\begin{tabular}{|c|c|c|c|c|c|c|}
\hline No & 213 & 74.5 & 18.0 & 28.0 & 10.0 & 18.0 \\
\hline Yes & 73 & 25.5 & 18.0 & 27.0 & 12.0 & 15.0 \\
\hline
\end{tabular}

0.02

0.678

Mental health status (self-assessed on a Likert-scale of 1-5)

$\begin{array}{llllllll}1 & 19 & 6.6 & 29.0 & 35.0 & 23.5 & 11.5 & 214.3 \\ 2 & 59 & 20.6 & 24.0 & 33.0 & 16.0 & 17.0 & 188.6 \\ 3 & 89 & 31.1 & 21.0 & 28.0 & 13.0 & 15.0 & 155.7 \\ 4 & 94 & 32.9 & 12.0 & 19.0 & 8.0 & 11.0 & 106.6 \\ & 25 & 8.7 & 6.0 & 16.0 & 4.0 & 12.0 & 78.5\end{array}$

Ever attempted suicide

$\begin{array}{llllllll}\text { No } & 273 & 95.5 & 18.0 & 27.0 & 10.0 & 17.0 & 140.7 \\ \text { Yes } & 13 & 4.5 & 27.0 & 31.0 & 22.0 & 9.0 & 201.6\end{array}$

Monthly household income in US dollars

$\begin{array}{llllllll}\text { Low }(<850) & 15 & 5.2 & 28.0 & 35.0 & 20.5 & 14.5 & 194.8 \\ \text { Medium (850-1400) } & 90 & 31.5 & 18.5 & 26.0 & 11.0 & 15.0 & 143.5 \\ \text { High }(>1400) & 181 & 63.3 & 17.0 & 27.0 & 10.0 & 17.0 & 139.3\end{array}$

Financial status (self-assessed on a Likert-scale of 1-5)

1 
Table 5 Association between characteristics of the participants and symptoms of anxiety (Continued)

\begin{tabular}{|c|c|c|c|c|c|c|c|c|c|c|}
\hline Characteristic & $n$ & $\%$ & Median & Q3 & Q1 & IQR & Mean rank & $p$-value & Correlation coefficient & $p$-value \\
\hline 2 & 24 & 8.4 & 27.5 & 31.5 & 17.5 & 14.0 & 192.0 & & & \\
\hline 3 & 96 & 33.6 & 19.0 & 27.0 & 11.0 & 16.0 & 148.9 & & & \\
\hline 4 & 105 & 36.7 & 16.0 & 25.0 & 9.0 & 16.0 & 134.6 & & & \\
\hline 5 & 57 & 19.9 & 16.0 & 25.0 & 7.0 & 18.0 & 128.5 & & & \\
\hline \multicolumn{11}{|l|}{ Marital status } \\
\hline Single & 277 & 96.9 & 18.0 & 27.0 & 10.0 & 17.0 & 143.0 & 0.533 & 0.04 & 0.534 \\
\hline Engaged/Married & 9 & 3.1 & 21.0 & 36.0 & 12.0 & 24.0 & 160.4 & & & \\
\hline \multicolumn{11}{|c|}{ Social life (self-assessed on a Likert-scale of 1-5) } \\
\hline 1 & 9 & 3.1 & 24.0 & 25.0 & 21.0 & 4.0 & 177.8 & 0.000 & -0.25 & 0.000 \\
\hline 2 & 33 & 11.5 & 27.0 & 35.0 & 16.0 & 19.0 & 194.3 & & & \\
\hline 3 & 74 & 25.9 & 20.0 & 30.0 & 11.3 & 18.8 & 155.0 & & & \\
\hline 4 & 96 & 33.6 & 16.0 & 24.0 & 9.0 & 15.0 & 131.5 & & & \\
\hline 5 & 74 & 25.9 & 15.0 & 23.0 & 6.3 & 16.8 & 120.7 & & & \\
\hline \multicolumn{11}{|c|}{ Religious commitment (self-assessed on a Likert-scale of 1-5) } \\
\hline 1 & 26 & 9.1 & 18.5 & 30.0 & 14.3 & 15.8 & 167.0 & 0.143 & -0.13 & 0.030 \\
\hline 2 & 41 & 14.3 & 19.0 & 26.0 & 13.0 & 13.0 & 153.5 & & & \\
\hline 3 & 114 & 39.9 & 18.0 & 28.0 & 11.0 & 17.0 & 147.9 & & & \\
\hline 4 & 96 & 33.6 & 15.0 & 27.3 & 7.0 & 20.3 & 130.9 & & & \\
\hline 5 & 9 & 3.1 & 13.0 & 22.0 & 3.0 & 19.0 & 108.7 & & & \\
\hline
\end{tabular}

Q1 1st quartile, Q3 3rd quartile, IQR: interquartile range

the Mann-Whitney U, Kruskal-Wallis, and correlation tests were retained in the multiple linear regression analysis, characteristics like academic stage $(p$-value $<0.05)$ and mental health status $(p$-value $<0.001)$ remained significantly associated.

Other variables like age, motives for studying medicine, ever attempted suicide, income, self-rated financial status, social life, and religious commitment were no longer significantly associated ( $p$-value $>0.05$ ). Details of the multiple linear analysis are shown in Table 6.

\section{Discussion}

The present study is the first report on the prevalence of depressive and anxiety symptoms among
Palestinian medical students and factors associated with symptoms of depression and anxiety. In this study, $23.1 \%$ of the medical students had moderate to severe depression and $46.8 \%$ had moderate to severe anxiety. High prevalence of depression and anxiety among medical students is a global phenomenon and despite the significant changes in medical education, this phenomenon continues to escalate on an apparently global level. While previous studies have investigated psychological distress among the general population or patients [59], little efforts were paid towards medical students in Palestine as an independent subgroup with distinct characteristics and predictors. The current study provides for the first time insights

Table 6 Multiple linear regression analysis of association between characteristics of the participants and anxiety symptoms

\begin{tabular}{|c|c|c|c|c|c|}
\hline Variable & Unstandardized Coefficients & S.E. & Standardized Coefficients & $\mathrm{t}$ & $p$-value \\
\hline$\overline{\text { Age }}$ & -1.00 & 1.64 & -0.04 & -0.61 & 0.543 \\
\hline Motives for studying medicine & 0.55 & 1.05 & 0.03 & 0.53 & 0.599 \\
\hline Academic stage & -3.42 & 1.58 & -0.15 & -2.16 & 0.031 \\
\hline Mental health status & -4.28 & 0.62 & -0.40 & -6.86 & 0.000 \\
\hline Ever attempted suicide & 5.10 & 2.87 & 0.09 & 1.78 & 0.076 \\
\hline Monthly household income & 0.29 & 1.21 & 0.02 & 0.24 & 0.810 \\
\hline Financial status & -0.61 & 0.79 & -0.05 & -0.77 & 0.441 \\
\hline Social life status & -0.79 & 0.64 & -0.07 & -1.23 & 0.221 \\
\hline Religious commitment status & -0.26 & 0.66 & -0.02 & -0.39 & 0.693 \\
\hline
\end{tabular}


into the prevalence of depressive and anxiety symptoms among Palestinian medical students.

Prevalence rates of depressive and anxiety symptoms among Palestinian medical students were comparable to those reported in a meta-analysis of 62,728 medical students pooled from 77 studies which reported a prevalence rate of $28.0 \%$ [18]. Our findings showed that cumulatively, mild to severe depressive symptoms were prevalent in $43.4 \%$ and mild to severe anxiety symptoms were prevalent in $76.6 \%$ of the medical students who took part in the study. Previous studies have shown that prevalence rates of depression and anxiety varied significantly $[8,10,11,13,16]$. Depression was prevalent in $57.9,40.4,30.6$, and $14.0 \%$ among medical students in Egypt [16], Bahrain [2], Estonia [12], and Lithuania [10], respectively. While anxiety was prevalent in 43.9, 51.0, 21.9, and 43.0\% among medical students in Egypt [16], Bahrain [2], Estonia [12], and Lithuania [10], respectively. It has been argued that differences in prevalence rates could be explained by differences in culture and religion. Culture and religion have been shown to shape emotions.

It was not surprising that $4.5 \%$ of the students who participated in this study stated that they had attempted suicide. It has been argued that the psychological environments provided in medical schools are toxic where students are under constant academic and social pressures, demanding workloads, financial concerns, deprivation of sleep, mistreatments, and exposure to sufferings of the patients $[1,9,60,61]$. These stressor factors affected medical students' academic performance, dropout rates, substance abuse, and suicidal ideation [37, 62]. In this study, depressive and anxiety symptoms were significantly higher for students who cited family motives behind opting to study medicine. Probably, many medical students are persuaded and pressurized by their families to study medicine. Similarly, depressive symptoms were more severe in students who stated that would not consider studying medicine again if they were given a second chance. Depressive and anxiety symptoms were also significantly higher in students in their basic academic years (years 1-3) than those in clinical years (years 4-6). Our findings were consistent with those reported in previous studies [11, 17]. Depressive and anxiety symptoms were associated with the selfrated mental health, financial status, social life, and religious commitment. Findings of this study were consistent with those reported previously by Pillay et al. in which depressive and anxiety symptoms were significantly more in medical students with history of poor mental health [35]. The study also showed association between spirituality and depressive symptoms. Other studies that have examined financial status found that financial difficulties within the previous 12 months were considered to be a stressful life event [14]. A study conducted in Germany found an association between financial hardships with poor mental health [20]. Comparisons of depressive symptoms by gender among medical students yielded mixed findings with some showing no difference or a much higher prevalence among female medical students [4, 18]. In this study, gender was not associated with depressive and anxiety symptoms. Studies that found gender to be significant factor proposed that there were a multitude of reasons for female students to be depressed including social stigma, gender inequality, and cultural pressures $[4,18]$. Our study found that the burden is shared equally between both genders. After controlling for confounding effects in the multiple regression analyses, academic stage and mental health status remained significantly associated with depressive and anxiety symptoms (Table 4 and Table 6). These results were consistent with those reported elsewhere [11, 17, 19, 35, 63].

In this study, good response rate $(67.3 \%)$ was obtained and the number of students who completed the study was higher than some of the recent studies conducted in the region $[2,16]$. The female gender was well represented $(60.8 \%)$ in our sample, this representation reflected a similar percentage of female medical students in Palestine. Similarly, the vast majority (96.9\%) of the students who took part in the study were single (Table 1). Little more than half (56.6\%) of the sample was students in their basic stage (academic year 1 to academic year 3), again this mirrored approximately similar distribution of students in these stages.

Findings of this study provide insights into psychological distress and morbidity among medical students in Palestine. It has been argued that providing insights into psychological distress and morbidity might help set policies and plan cognitive, behavioral, and mindful interventions that might be effective in minimizing depressive and anxiety symptoms in these subpopulations [64, 65]. Our results could be helpful to policy and decision makers in healthcare and educational authorities to take measures and design interventions to reduce depressive and anxiety symptoms among medical students in Palestine.

\section{Limitations}

Findings of this study be should interpreted considering the following limitations. First, this was a cross-sectional observational study. Ideally, our study should have been further explored in a longitudinal, large, prospective multicenter study with greater detail in examining stressors. Second, as the inventories in the current study were self-administered, it is likely that some students may have downplayed some of their depressive and anxiety symptoms or answered the question about previous 
suicidal attempts untruthfully due to fear of social stigma. Third, in the study, all students were recruited from one Palestinian university. However, to establish a true baseline for Palestinian medical schools, this research should have been conducted on a national level in all three Palestinian medical schools. It is noteworthy mentioning that the study was conducted in the largest university in Palestine. Fourth, although the sample size of this study was comparatively higher than those used in the studies conducted in the region $[2,16]$, a larger sample size could have increased the rigor of the current study. Fifth, although depressive and anxiety symptoms were assessed using two valid selfadministered inventories, no further clinical assessments were conducted by psychologists or psychiatrists to assess depression and anxiety among the participants in this study. Sixth, the students who took part in this study were asked if they had ever attempted suicide. As the students could have depression and anxiety as a co-morbidity, answers of the students should be interpreted with caution as the findings could have been biased. Finally, we did not investigate the effects of family support, resilience, and coping skills of the students with regards to depression and anxiety. Many studies have shown that these factors could also improve health and impact prevalence of depression and anxiety among medical students $[66,67]$.

\section{Conclusions}

Our findings strongly suggest that depressive and anxiety symptoms are prevalent among Palestinian medical students in a major university in the West Bank. Policy and decision makers in healthcare and educational authorities should consider addressing this issue of concern. Interventions designed to improve self-rated mental health, those targeting students in their early academic years, improving study conditions, and counseling to improve spirituality could be effective in reducing symptoms of depression among medical students in Palestine. However, interventions designed to improve self-rated mental health and those targeting students in their early academic years could be effective in reducing symptoms of anxiety among medical students in Palestine. Future studies are still needed to investigate if these interventions could be useful in reducing depressive and anxiety symptoms among Palestinian medical students.

\section{Supplementary information}

Supplementary information accompanies this paper at https://doi.org/10. 1186/s12888-020-02658-1.

Additional file 1. Items in the Beck Depression Inventory-II (BDI-II)

Additional file 2. Items in the Beck Anxiety Inventory (BAl)

\section{Abbreviations}

BAl: Beck Anxiety Inventory; BDI-II: Beck Depression Inventory-II;

$\mathrm{Cl}$ : Confidence interval; GPA: Grade Point Average; IQR: Interquartile range;
Q1: Lower quartile; Q3: Upper quartile; VIF: Variance inflation factor; WHO: World Health Organization

\section{Acknowledgements}

Authors would like to thank the students who participated in this study. AnNajah National University is acknowledged for facilitating and making this study possible.

\section{Authors' contributions}

RS and SH conceived the study. RA and MT collected the data. RS, RA and MT analyzed the data. RS, SH, RA and MT interpreted the findings. RS, SH, RA and MT drafted the first version of the manuscript. RS wrote the final manuscript. The study was based on a graduation project for the students RA and MT. SH and RS were the academic supervisors of the project and both share the corresponding author status. Both corresponding authors can be reached the same postal address. RS can also be reached through his email address: ramzi.shawahna@najah.edu. Order of the authors was consensual and based on the contribution of the researchers to the study. All authors read and approved the manuscript.

Funding

Not applicable.

\section{Availability of data and materials}

Data related to this study are either presented in the results section or in the additional files. Raw data can be obtained from the corresponding author upon reasonable request.

Ethics approval and consent to participate

The study was conducted in accordance with the regulations and ethics followed at An-Najah National University and in compliance with the Declaration of Helsinki. The study received ethical approval from the Institutional Review Board (IRB) of An-Najah National University (Protocol \# April-04-2018). Each participant provided written informed consent before taking part in the study.

Consent for publication

Not applicable.

\section{Competing interests}

The authors declare that they have no competing interests.

\section{Author details}

1Department of Physiology, Pharmacology and Toxicology, Faculty of Medicine and Health Sciences, An-Najah National University, New Campus, Building 19, P.O. Box 7, Nablus, Palestine. ${ }^{2}$ An-Najah BioSciences Unit, Centre for Poisons Control, Chemical and Biological Analyses, An-Najah National University, Nablus, Palestine. ${ }^{3}$ Department of Medicine, Faculty of Medicine and Health Sciences, An-Najah National University, Nablus, Palestine.

Received: 19 September 2019 Accepted: 11 May 2020

Published online: 19 May 2020

\section{References}

1. January J, Madhombiro M, Chipamaunga S, Ray S, Chingono A, Abas M. Prevalence of depression and anxiety among undergraduate university students in low- and middle-income countries: a systematic review protocol. Syst Rev. 2018;7(1):57.

2. Mahroon ZA, Borgan SM, Kamel C, Maddison W, Royston M, Donnellan C. Factors associated with depression and anxiety symptoms among medical students in Bahrain. Acad Psychiatry. 2018;42(1):31-40.

3. Fawzy M, Hamed SA. Prevalence of psychological stress, depression and anxiety among medical students in Egypt. Psychiatry Res. 2017;255:186-94.

4. Azad N, Shahid A, Abbas N, Shaheen A, Munir N. Anxiety and depression in medical students of a private medical college. J Ayub Med Coll Abbottabad. 2017:29(1):123-7.

5. Cuttilan AN, Sayampanathan AA, Ho RC-M. Mental health issues amongst medical students in Asia: a systematic review [2000-2015]. Ann Transl Med. 2016, 4(4).

6. Brenneisen Mayer F, Souza Santos I, Silveira PS, Itaqui Lopes MH, de Souza AR, Campos EP, de Abreu BA, Hoffman li I, Magalhaes CR, Lima MC, et al. 
Factors associated to depression and anxiety in medical students: a multicenter study. BMC Med Educ. 2016;16(1):282.

7. Hope V, Henderson M. Medical student depression, anxiety and distress outside North America: a systematic review. Med Educ. 2014;48(10):963-79.

8. Alvi T, Assad F, Ramzan M, Khan FA. Depression, anxiety and their associated factors among medical students. J Coll Phys Surg. 2010;20(2): 122-6.

9. Borst JM, Frings-Dresen MH, Sluiter JK. Prevalence and incidence of mental health problems among Dutch medical students and the study-related and personal risk factors: a longitudinal study. Int J Adolesc Med Health. 2016; 28(4):349-55.

10. Bunevicius A, Katkute A, Bunevicius R. Symptoms of anxiety and depression in medical students and in humanities students: relationship with big-five personality dimensions and vulnerability to stress. Int J Soc Psychiatry. 2008; 54(6):494-501.

11. Ediz B, Ozcakir A, Bilgel N. Depression and anxiety among medical students: examining scores of the beck depression and anxiety inventory and the depression anxiety and stress scale with student characteristics. Cogent Psychol. 2017;4(1):1283829.

12. Eller T, Aluoja A, Vasar V, Veldi M. Symptoms of anxiety and depression in Estonian medical students with sleep problems. Depression Anxiety. 2006; 23(4):250-6

13. Goebert D, Thompson D, Takeshita J, Beach C, Bryson P, Ephgrave K, Kent A, Kunkel M, Schechter J, Tate J. Depressive symptoms in medical students and residents: a multischool study. Acad Med. 2009;84(2):236-41.

14. Hojat M, Glaser K, Xu G, Veloski JJ, Christian EB. Gender comparisons of medical students' psychosocial profiles. Med Educ. 1999;33(5):342-9.

15. Ibrahim AK, Kelly SJ, Adams CE, Glazebrook C. A systematic review of studies of depression prevalence in university students. J Psychiatr Res. 2013:47(3):391-400.

16. Ibrahim MB, Abdelreheem MH. Prevalence of anxiety and depression among medical and pharmaceutical students in Alexandria University. Alexandria J Med. 2015;51(2):167-73.

17. Karaoglu N, Seker M. Anxiety and depression in medical students related to desire for and expectations from a medical career. West Ind Med J. 2010; 59(2):196-202.

18. Puthran R, Zhang MW, Tam WW, Ho RC. Prevalence of depression amongst medical students: a meta-analysis. Med Educ. 2016;50(4):456-68.

19. Roh MS, Jeon HJ, Kim H, Han SK, Hahm BJ. The prevalence and impact of depression among medical students: a nationwide cross-sectional study in South Korea. Acad Med. 2010;85(8):1384-90.

20. Wege N, Muth T, Li J, Angerer P. Mental health among currently enrolled medical students in Germany. Public Health. 2016;132:92-100.

21. Albajjar MA, Bakarman MA. Prevalence and correlates of depression among male medical students and interns in Albaha University, Saudi Arabia. J Family Med Prim Care. 2019;8(6):1889-94.

22. Alharbi H, Almalki A, Alabdan F, Haddad B. Depression among medical students in Saudi medical colleges: a cross-sectional study. Adv Med Educ Pract. 2018:9:887-91.

23. Hamasha AA, Kareem YM, Alghamdi MS, Algarni MS, Alahedib KS, Alharbi FA. Risk indicators of depression among medical, dental, nursing, pharmacology, and other medical science students in Saudi Arabia. Int Rev Psychiatry. 2019;31(7-8):646-52.

24. Ibrahim N, Al-Kharboush D, El-Khatib L, Al-Habib A, Asali D. Prevalence and predictors of anxiety and depression among female medical students in king Abdulaziz University, Jeddah, Saudi Arabia. Iran J Public Health. 2013; 42(7):726-36.

25. Inam SB. Anxiety and depression among students of a medical College in Saudi Arabia. Int J Health Sci (Qassim). 2007;1(2):295-300

26. Dahlin ME, Runeson B. Burnout and psychiatric morbidity among medical students entering clinical training: a three year prospective questionnaire and interview-based study. BMC Med Educ. 2007;7:6-6.

27. Dyrbye LN, West CP, Satele D, Boone S, Tan L, Sloan J, Shanafelt TD. Burnout among U.S. medical students, residents, and early career physicians relative to the general U.S. population. Acad Med. 2014;89(3):443-51.

28. Bacchi S, Licinio J. Qualitative literature review of the prevalence of depression in medical students compared to students in non-medical degrees. Acad Psychiatry. 2015;39(3):293-9.

29. Tempski P, Bellodi PL, Paro HB, Enns SC, Martins MA, Schraiber LB. What do medical students think about their quality of life? A qualitative study. BMC Med Educ. 2012;12:106
30. Lu Y, Tang C, Liow CS, Ng WW, Ho CS, Ho RC. A regressional analysis of maladaptive rumination, illness perception and negative emotional outcomes in Asian patients suffering from depressive disorder. Asian J Psychiatr. 2014;12:69-76.

31. Lim GY, Tam WW, Lu Y, Ho CS, Zhang MW, Ho RC. Prevalence of depression in the community from 30 countries between 1994 and 2014. Sci Rep. 2018; 8(1):2861

32. Lader M: Generalized Anxiety Disorder. In: Encyclopedia of Psychopharmacology. edn. Edited by Stolerman IP, Price LH. Berlin, Heidelberg: Springer Berlin Heidelberg; 2015: 699-702.

33. Gracino ME, Zitta ALL, Mangili OC, Massuda EM. A saúde física e mental do profissional médico: uma revisão sistemática. Saúde em Debate. 2016; 40(110):244-63.

34. Rahman A, Patel V, Maselko J, Kirkwood B. The neglected ' $m$ ' in MCH programmes--why mental health of mothers is important for child nutrition. Trop Med Int Health. 2008;13(4):579-83

35. Pillay N, Ramlall S, Burns JK. Spirituality, depression and quality of life in medical students in KwaZulu-Natal. S Afr J Psychiatr. 2016;22(1):731.

36. Ip EJ, Nguyen K, Shah BM, Doroudgar S, Bidwal MK. Motivations and predictors of cheating in pharmacy school. Am J Pharm Educ. 2016;80(8): 133.

37. Walkiewicz M, Tartas M, Majkowicz M, Budzinski W. Academic achievement, depression and anxiety during medical education predict the styles of success in a medical career: a 10-year longitudinal study. Med Teach. 2012; 34(9):e611-9.

38. Stoen Grotmol K, Gude T, Moum T, Vaglum P, Tyssen R. Risk factors at medical school for later severe depression: a 15-year longitudinal, nationwide study (NORDOC). J Affect Disord. 2013;146(1):106-11.

39. Beck AT, Steer RA, Brown GK: Beck depression inventory-II, 2nd edn. San Antonio, TX: Psychological Corporation; 1996.

40. Beck AT, Epstein N, Brown G, Steer RA. An inventory for measuring clinical anxiety: psychometric properties. J Consult Clin Psychol. 1988;56(6):893-7.

41. Shawahna R, Jaber M. Assessing knowledge and attitudes of Palestinian undergraduate nursing students toward epilepsy and patients with epilepsy: a cross-sectional study. Epilepsy Behav. 2020;102:106811.

42. Shawahna R. Facilitating ethical, legal, and professional deliberations to resolve dilemmas in daily healthcare practice: a case of driver with breakthrough seizures. Epilepsy Behav. 2020;102:106703.

43. Shraim NY, Shawahna R, Sorady MA, Aiesh BM, Alashqar GS, Jitan Rl, Abu Hanieh WM, Hotari YB, Sweileh WM, Zyoud SH. Community pharmacists knowledge, practices and beliefs about complementary and alternative medicine in Palestine: a cross-sectional study. BMC Complement Altern Med. 2017;17(1):429.

44. Shawahna R, Khaskiyyi M, Abdo H, Msarwe Y, Odeh R, Salame S. Palestinian pharmacists' knowledge of issues related to using psychotropic medications in older people: a cross-sectional study. J Educ Eval Health Prof. 2017;14:8.

45. Shawahna R, Fahed B, Qadri D, Sharawi L, Soroghli M, Dweik M. Awareness and knowledge of autism Spectrum disorders among pharmacists: a crosssectional study in Palestinian pharmacy practice. J Autism Dev Disord. 2017; 47(6):1618-27

46. Shawahna R, Atrash A, Jebril A, Khalaf A, Shaheen E, Tahboosh H. Evaluation of pharmacists' knowledge of women's issues in epilepsy: a cross-sectional study in Palestinian pharmacy practice. Seizure. 2017;46:1-6.

47. Shawahna R, Atrash A, Jebril A, Khalaf A, Shaheen E, Tahboosh $H$. Pharmacists' knowledge of issues in pharmacotherapy of epilepsy using antiepileptic drugs: a cross-sectional study in Palestinian pharmacy practice. Epilepsy Behav. 2017:67:39-44.

48. Shawahna R, Jaradat NA. Ethnopharmacological survey of medicinal plants used by patients with psoriasis in the West Bank of Palestine. BMC Complement Altern Med. 2017;17(1):4.

49. Shawahna R, Al-Rjoub M, Al-Horoub MM, Al-Hroub W, Al-Rjoub B, AlNabi BA. Risk of error estimated from Palestine pharmacists' knowledge and certainty on the adverse effects and contraindications of active pharmaceutical ingredients and excipients. J Educ Eval Health Prof. 2016;13:1

50. Shawahna R, Debay M, Rahman NU. Inequalities in health care and behaviour in patients with diabetes and concurrent hypertension in Lahore, Pakistan. Tanzan J Health Res. 2013;15(4):240-6.

51. Smarr KL, Keefer AL. Measures of depression and depressive symptoms: Beck depression inventory-II (BDI-II), Center for Epidemiologic Studies Depression Scale (CES-D), geriatric depression scale (GDS), hospital anxiety 
and depression scale (HADS), and patient health Questionnaire-9 (PHQ-9). Arthritis Care Res. 2011;63(Suppl 11):S454-66.

52. Homaifar BY, Brenner LA, Gutierrez PM, Harwood JF, Thompson C, Filley CM, Kelly JP, Adler LE. Sensitivity and specificity of the Beck depression inventory-ll in persons with traumatic brain injury. Arch Phys Med Rehabil. 2009;90(4):652-6.

53. Manne S, Nereo N, DuHamel K, Ostroff J, Parsons S, Martini R, Williams S, Mee L, Sexson S, Lewis J, et al. Anxiety and depression in mothers of children undergoing bone marrow transplant: symptom prevalence and use of the Beck depression and Beck anxiety inventories as screening instruments. J Consult Clin Psychol. 2001;69(6):1037-47.

54. Abdel-Khalek AM. Internal consistency of an Arabic adaptation of the Beck depression inventory in four Arab countries. Psychol Rep. 1998;82(1):264-6.

55. Alansari BM. Gender differences in depression among undergraduates from seventeen Islamic countries. Soc Behav Personal Int J. 2006;34(6):729-38.

56. Alansari BM. Internal consistency of an Arabic adaptation of the Beck depression inventory-II with college students in eighteen Arab countries. Soc Behav Personal Int J. 2006;34(4):425-30.

57. Shawahna R, Zyoud A, Jallad D, Hadwan L, Ihssan N, Hilal H. Blood zinc levels in nursing women from different regions of the West Bank of Palestine. Women Health. 2018;58(7):822-33.

58. Shawahna R, Zyoud A, Dwikat J, El-Helo M, Yacoub B, Hilal H. Breast Milk Lead levels in 3 major regions of the West Bank of Palestine. J Hum Lactation. 2016;32(3):455-61.

59. Madianos MG, Sarhan AL, Koukia E. Posttraumatic stress disorders comorbid with major depression in West Bank, Palestine: a general population cross sectional study. Eur Psychiatr. 2011;25(1):19-31.

60. Bovero A, Tosi C, Miniotti M, Torta R, Leombruni P. Medical students reflections toward end-of-life: a hospice experience. J Cancer Educ. 2018; 33(3):634-9.

61. Cook AF, Arora VM, Rasinski KA, Curlin FA, Yoon JD. The prevalence of medical student mistreatment and its association with burnout. Acad Med. 2014:89(5):749-54.

62. Tyssen R, Vaglum P, Gronvold NT, Ekeberg O. Suicidal ideation among medical students and young physicians: a nationwide and prospective study of prevalence and predictors. J Affect Disord. 2001;64(1):69-79.

63. Bayram N, Bilgel N. The prevalence and socio-demographic correlations of depression, anxiety and stress among a group of university students. Soc Psychiatry Psychiatr Epidemiol. 2008:43(8):667-72.

64. McConville J, McAleer R, Hahne A. Mindfulness training for health profession students-the effect of mindfulness training on psychological well-being, learning and clinical performance of health professional students: a systematic review of randomized and non-randomized controlled trials. Explore (NY). 2017;13(1):26-45.

65. Regehr C, Glancy D, Pitts A. Interventions to reduce stress in university students: a review and meta-analysis. J Affect Disord. 2013;148(1):1-11.

66. Hassed C, de Lisle S, Sullivan G, Pier C. Enhancing the health of medical students: outcomes of an integrated mindfulness and lifestyle program. Adv Health Sci Educ. 2009;14(3):387-98.

67. Henning MA, Shulruf B, Hawken SJ, Pinnock R. Changing the learning environment: the medical student voice. Clin Teach. 2011;8(2):83-7.

\section{Publisher's Note}

Springer Nature remains neutral with regard to jurisdictional claims in published maps and institutional affiliations.

Ready to submit your research? Choose BMC and benefit from:

- fast, convenient online submission

- thorough peer review by experienced researchers in your field

- rapid publication on acceptance

- support for research data, including large and complex data types

- gold Open Access which fosters wider collaboration and increased citations

- maximum visibility for your research: over $100 \mathrm{M}$ website views per year

At BMC, research is always in progress.

Learn more biomedcentral.com/submissions 